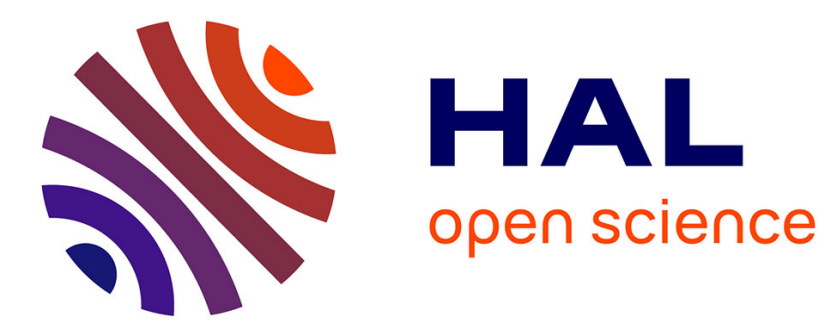

\title{
The mixing height in urban areas: comparative study for Copenhagen
}

\author{
A. Baklanov, A. Kuchin
}

\section{To cite this version:}

A. Baklanov, A. Kuchin. The mixing height in urban areas: comparative study for Copenhagen. Atmospheric Chemistry and Physics Discussions, 2004, 4 (3), pp.2839-2866. hal-00301262

\section{HAL Id: hal-00301262 \\ https://hal.science/hal-00301262}

Submitted on 24 May 2004

HAL is a multi-disciplinary open access archive for the deposit and dissemination of scientific research documents, whether they are published or not. The documents may come from teaching and research institutions in France or abroad, or from public or private research centers.
L'archive ouverte pluridisciplinaire HAL, est destinée au dépôt et à la diffusion de documents scientifiques de niveau recherche, publiés ou non, émanant des établissements d'enseignement et de recherche français ou étrangers, des laboratoires publics ou privés. 
Atmos. Chem. Phys. Discuss., 4, 2839-2866, 2004

www.atmos-chem-phys.org/acpd/4/2839/

SRef-ID: 1680-7375/acpd/2004-4-2839

(C) European Geosciences Union 2004
ACPD

4, 2839-2866, 2004

Mixing height for

Copenhagen

A. Baklanov and

A. Kuchin

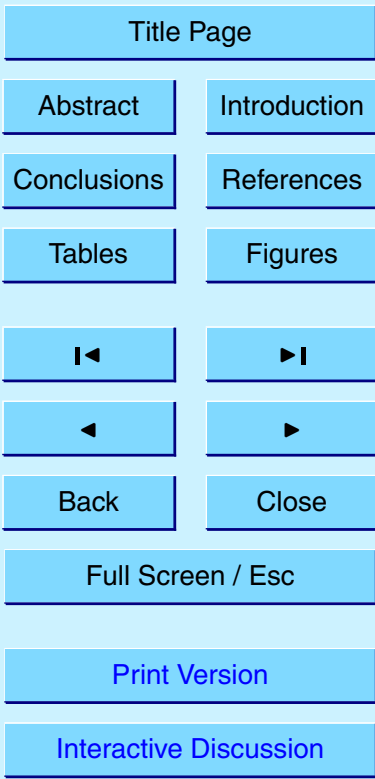

(C) EGU 2004 


\section{Abstract}

The urban boundary layer (UBL), in comparison with "rural" homogeneous atmospheric boundary layers, is characterised by greatly enhanced mixing, resulting from both the large surface roughness and increased surface heating, and by horizontal heterogene5 ity of the mixing height $(\mathrm{MH})$ and other meteorological fields due to variations in surface roughness and heating from rural to central city areas. So, the UBL is considered as a specific case of the atmospheric boundary layer $(\mathrm{ABL})$ over a non-homogeneous terrain. Therefore it is important to study how much the $\mathrm{MH}$ characteristics differ in urban and rural, marine or other more homogeneous areas. Most of the parameterisations of

$\mathrm{MH}$ were developed for the conditions of a homogeneous terrain, so their applicability for urban conditions should be verified. Just a few authors suggested specific methods for $\mathrm{MH}$ determination in urban areas. In this paper the $\mathrm{MH}$ over urban, semi-urban, rural and marine areas of the Copenhagen metropolitan area is considered. Proceeding from the data from the Jægersborg radiosounding station measurement and analysis of different methods of the MH estimation, the peculiarities of the UBL and intercomparison of different $\mathrm{MH}$ estimation methods for urban and rural conditions are discussed. It is shown that the urban $\mathrm{MH}$ is considerably bigger for stably stratified (nocturnal) boundary layer cases in comparison with the "non-urban" MH. Daytime (usually the convective boundary layer) $\mathrm{MH}$ does not differ significatly in urban and "non-urban" sectors.

\section{Introduction}

Most of the urban atmospheric pollution models request the mixing layer height $(\mathrm{MH})$ as input. $\mathrm{MH}$ is not observed by standard measurements. In dispersion models it can be parameterised or obtained from profile measurements or simulations. The COSTAction 710 (Seibert et al., 1998) reviewed different definitions and estimations of $\mathrm{MH}$ based on the measurements, modelling, parameterisations, and numerical weather
ACPD

4, 2839-2866, 2004

Mixing height for Copenhagen

A. Baklanov and

A. Kuchin

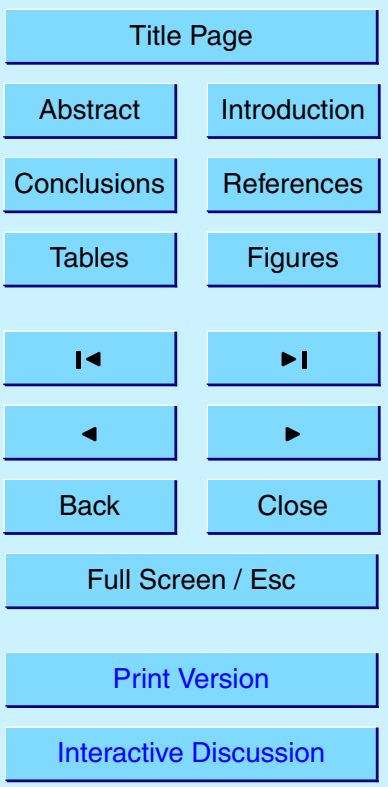

(C) EGU 2004 
prediction (NWP) model outputs. The follow-up COST-Action 715 (Fisher et al., 2001) developed the scientific work achieved under COST-710 from rural to urban conditions. In particular, the Working Group 2 focuses on specific problems in describing the surface energy balance and $\mathrm{MH}$ in urban areas (Piringer et al., 2001).

5 The urban boundary layer (UBL), in comparison with "rural" homogeneous ABLs, is characterised by drastic changes in the surface roughness and urban surface heat fluxes. As a result, there are several aspects for analysing the urban $\mathrm{MH}$, including:

(i) urban internal boundary layer (IBL),

(ii) elevated nocturnal inversion layer,

10 (iii) strong horizontal inhomogeneity and temporal non-stationarity,

(iv) so-called "urban roughness island", zero-level of urban canopy, and $z_{0 u} \neq z_{0 T}$,

(v) anthropogenic heat fluxes from street to city scale,

(vi) downwind "urban plume" and scale of urban effects in space and time,

(vii) calm weather situation,

15 (viii) non-local character of urban $\mathrm{MH}$ formation,

(ix) effect of the water vapour fluxes.

During the last decades, many experimental studies of the mixing layer were realised for urban areas. This made it possible to analyse effects of the urban peculiarities and verify different methods of the $\mathrm{MH}$ estimation versus measurement datasets from several types of urban areas.

Proceeding from the urban area features, there are the following important questions to answer when analysing the urban $\mathrm{MH}$ based on experimental data:

- How much does the $\mathrm{MH}$ in urban areas differ from the rural $\mathrm{MH}$ ?

Mixing height for Copenhagen

A. Baklanov and A. Kuchin

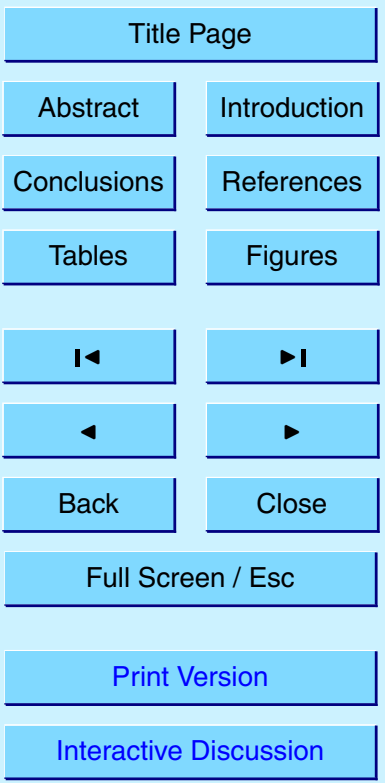

(c) EGU 2004 
- How does the temporal dynamics of MH in urban areas differ from the rural $\mathrm{MH}$ ?

- What is the scale of urban effects in space, e.g. downwind "urban plume" effect on $\mathrm{MH}$ ?

- How important is the urban IBL in forming the MH?

5 Several experimental studies analysed differences of $\mathrm{MH}$ in urban and rural sites for different geographical regions (see overview, e.g. in Baklanov, 2002). There are several geographically different types of cities (e.g. on a flat terrain or in mountain valleys, coastal, northern or southern cities), peculiarities of each type can affect the formation of UBL as well. For example, the stably stratified nocturnal boundary layer is not common for USA cities (Bornstein, 2001), and it could be an elevated nocturnal inversion layer only. However, for European cities (especially in the Northern Europe) the nocturnal, stably-stratified boundary layer $(\mathrm{SBL})$ is very common (e.g. Helsinki or Copenhagen). In previous years there were several UBL experimental studies in European cities: Athens, Copenhagen, Munich, Paris, Vienna, etc. Unfortunately, many 15 of them are not complete for verification of the $\mathrm{MH}$ estimation methods, because they didn't include direct measurements of MH. For WG2 COST 715 purposes the most suitable datasets for European cities are prepared from the BUBBLE and ESCOMPTE experiments in Basel (Rotach et al., 2002) and Marseille (Mestayer et al., 2003), respectively.

20 However, in operational or climatologic atmospheric pollution studies, for the $\mathrm{MH}$ estimation one has to base on operationally available routine measurements or NWP simulations.

In general sense, the $\mathrm{MH}$ can be estimated experimentally based on different methods of vertical profile measurements by several means/criteria, e.g.:

- height where turbulence diminishes, or heat flux diminishes (for example, $5 \%$ ),

- height of discontinuity in profiles of wind/temperature/dew point (radiosonde or commercial aircraft data).

Mixing height for Copenhagen

A. Baklanov and A. Kuchin

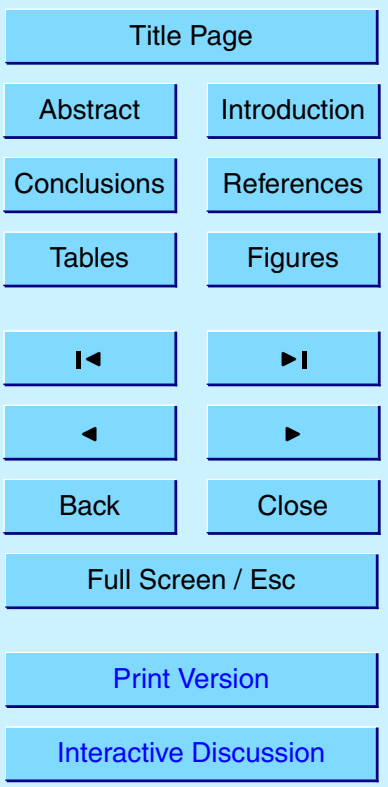

(C) EGU 2004 
The main idea of the paper is to study the differences of the urban/rural MHs in the Copenhagen area and to suggest a suitable way for the $\mathrm{MH}$ estimation, based on available vertical daily measurement data, for dispersion models in climatic studies or for operational urban air quality forecasting models.

The following research questions will be touched in this paper:

1. Urban features for the Copenhagen area effecting the $\mathrm{MH}$ formation. How much is the difference between urban/rural $\mathrm{MH}$, and when?

2. Most of operational MH methods use surface layer meteorological routine measurement data and simple parameterisation methods for the $\mathrm{MH}$. Is this way suitable for urban $\mathrm{MH}$ estimations?

3. Usually there is no operational data about vertical structure of BL in urban areas (Sodars or Lidars are not used usually operationally in cities). Therefore, it is important to analyse a possibility to use radiosounding data (such stations are usually located close to cities) and commercial aircraft measurements (available for most of megacities) or some future remote sensing methods (e.g. GPS profiling) for the $\mathrm{MH}$ estimation. Is it possible to use such data for operational models or better to use NWP profiles for MH estimation in urban areas?

\section{Study area of greater Copenhagen}

The Copenhagen metropolitan area (Greater Copenhagen) was chosen for the comparison of methods and experimental studies of the mixing layer features in urban conditions. Figure 1 presents a map of the Copenhagen Metropolitan area and its surroundings with marked positions of meteorological measurement stations of DMI and other Danish research institutes. The radiosounding station of Jægersborg (marked by a big red ellipse on the map) is used for the $\mathrm{MH}$ studies. This station is situated inside
ACPD

4, 2839-2866, 2004

Mixing height for Copenhagen

A. Baklanov and

A. Kuchin

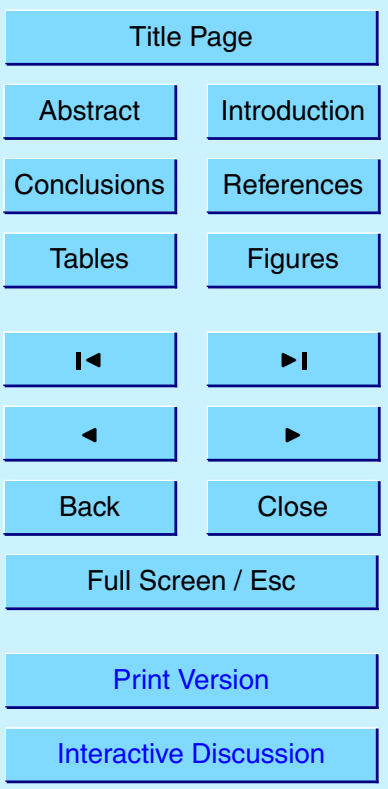

(C) EGU 2004 
is situated on a small hill ( $40 \mathrm{~m}$ above the sea level) with a relatively homogeneous and open surface $(\sim 100 \mathrm{~m})$, and surrounded by urban areas from $\mathrm{S}$, SW, and SE; semiurban and rural areas - from NW and N, and by a forest park in the coast area and the Øresund water surface from NE (see Fig. 1). Therefore, all measurements from 5 the radiosounding station were separated for analysis according to the wind direction from three corresponding sectors: 1) water and coastal forest, 2) urban areas of central Copenhagen, 3) rural and semi-urban areas. The sectors are separated on the map in Fig. 1 by the black lines. The effective roughnesses for these sectors are 1) $0.2 \mathrm{~m}, 2$ ) $1 \mathrm{~m}, 3) 0.3 \mathrm{~m}$ correspondingly.

10 Let us consider one 2001 year statistics of radiosounding vertical profiles from the Jægersborg station. This station is included in WMO database, but DMI radiosounding stations use a higher vertical resolution of measurements than the WMO standards, therefore, we will use the original data with the highest resolution. The Jægerborg station releases radiosonds twice a day: $12: 00$ and 24:00 of the local time (it corresponds following meteorological values is measured: pressure, wind velocity, wind direction, air temperature and dewpoint. Using these data vertical profiles of the potential $(\theta)$ and virtual $\left(\theta_{v}\right)$ temperatures, relative humidity $(q)$, and mixing ratio $(r)$ can be recalculated. The first lowest level measurements are done at $2 \mathrm{~m}$ for pressure, air temperature, and dewpoint; and at $10 \mathrm{~m}$ - for wind velocity and direction by separate instruments at the moment of the radiosonde launching. The next level of the radiosound measurements corresponds to $25-50 \mathrm{~m}$, and further measurements follow each $5 \mathrm{~s}$ with the vertical resolution of $25-50 \mathrm{~m}$ depending on the velocity of radiosonde lifting.

Additionally, wind and temperature vertical profile data for the Copenhagen area are available from measurements by commercial aircrafts departing or landing at the Kastrup airport (situated almost inside of the Greater Copenhagen, Fig. 1). Most of airplanes are equipped with on-board sensors of pressure, temperature, wind velocity, and will be equipped soon with moisture sensors. According to the EUMETNETAMDAR Project: Aircraft Meteorological Data Reporting (E-AMDAR, 2002), where DMI

\section{ACPD}

4, 2839-2866, 2004

Mixing height for Copenhagen

A. Baklanov and A. Kuchin

Title Page

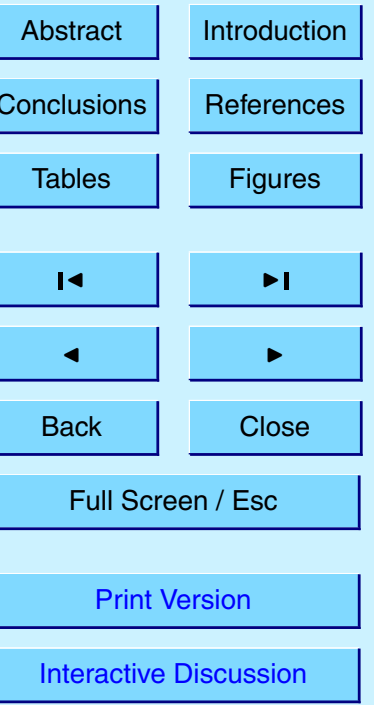

(C) EGU 2004 
participates, all meteorological data from the airplanes around Europe are transferred in the AMDAR communication system (AMDAR, 2003) and available operationally. The DMI-HIRLAM model already started to assimilate that data for the operational NWP. Quality of the data are already comparable with the radiosounding data and will be 5 increased in future, besides the aircraft measurements are much more frequent in time (excluding night-time). The commercial aircraft measurement data can be treated for the $\mathrm{MH}$ estimation by the same way as we use the radiosounding data.

\section{Choice of methods for the urban MH estimation}

Many $\mathrm{MH}$ parameterisations were developed for conditions of homogeneous terrain. 10 Their applicability for the urban conditions should be verified. Some authors suggested specific methods for the $\mathrm{MH}$ estimation in urban areas. They can be distinguished in two main categories: (i) with a local correction of the heat fluxes due to urban effects, and (ii) with estimations of the IBL height growth. The first category usually uses common methods for the homogeneous terrain with the urban heat fluxes and roughness.

15 The second category is based on general methods for the IBL height estimation for areas with abrupt/drastic change of the surface roughness.

During the last years, output data from 3-D NWP models were increasingly used for the $\mathrm{MH}$ estimation based on different approaches. Direct calculations of $\mathrm{MH}$ from simulated TKE or eddy profiles for the daytime UBLs showed promising results. However, 20

\section{this way is sensitive to turbulent closure. For the nocturnal MH it can give considerable} problems, e.g. from TKE equations with a local closure. For example, HIRLAM with the CBR scheme tested a direct calculation of MH from the TKE profile, and it showed an underestimation of the nocturnal $\mathrm{MH}$ (Baklanov, 2001).

Proceeding from analysis of different methods of the $\mathrm{MH}$ estimation in general (Seib25

ert et al., 1999) and for urban areas in particular (Baklanov, 2002), the below discussed methods can be tested for $\mathrm{MH}$ estimation based on vertical profiles of temperature, wind speed, and humidity. The available radiosounding data, used in this study, do not

\section{ACPD}

4, 2839-2866, 2004

Mixing height for Copenhagen

A. Baklanov and

A. Kuchin

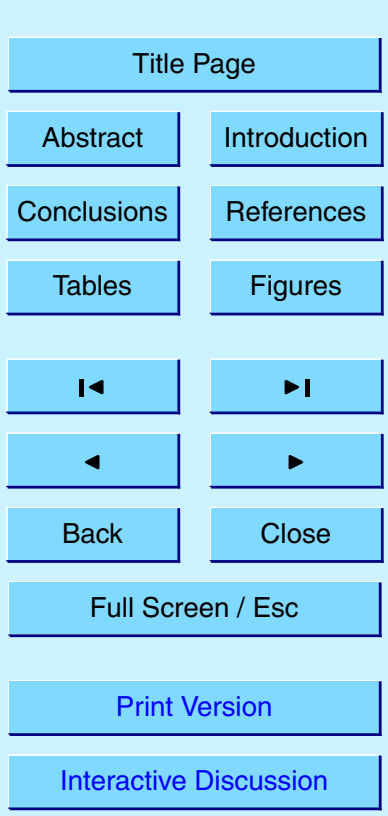

(C) EGU 2004 
have a suitable time resolution (only twice a day), therefore diagnostic methods will be used only.

The $\mathrm{MH}$ estimation from the radiosounding profile data for three sectors of the wind direction is considered. The following diagnostic methods for the $\mathrm{MH}$ estimation will 5 be tested (see descriptions of the methods in overviews by Seibert et al., 1998; Baklanov, 2002). For the convective boundary layer (CBL) cases (mostly daytime measurements): the bulk Richardson number method (RI), the simple Parcel method (PAR), advance Parcel method (PARADV), the humidity jump method (HJMP) and the experimental method of Benkley and Schulman (1979)(BS). For the SBL cases (nocturnal 10 measurements in majority): the bulk Richardson number method (RI), the maximum low-level jet velocity method (VMAX), the humidity jump method (HJMP) and several parameterisation methods from Table 1, in particular, the method of Arya (1981)(AR81) and the experimental method of Benkley and Schulman (1979)(BS).

The experimental or similarity theory parameterisation methods, considered in Ta15 ble 1, based on:

1. surface layer data (standard meteorological routine measurements and surface fluxes) - methods 1-6;

2. surface layer data and vertical profile info (the Brunt-Väisälä frequency over ABL is needed) - methods 7-8.

Because most of radiosounding stations do not measure directly the surface turbulent fluxes, we will avoid to use methods, which required values of the turbulent heat fluxes. Actually, the surface heat fluxes can be calculated from the lowest level pars of temperature, humidity, and wind velocity measurements, but it required additional sensitivity and uncertainty studies due to the measurements at $2 / 10 \mathrm{~m}$ and the first radiosonde signal $(\sim 30-40 \mathrm{~m})$ by different instruments, therefore, it will be a topic of separate studies.

Using the above mentioned and many other different methods for the $\mathrm{MH}$ diagnosis a new user-friendly computer tool for the $\mathrm{MH}$ estimation, inter-comparison and statis-

ACPD

4, 2839-2866, 2004

Mixing height for Copenhagen

A. Baklanov and

A. Kuchin

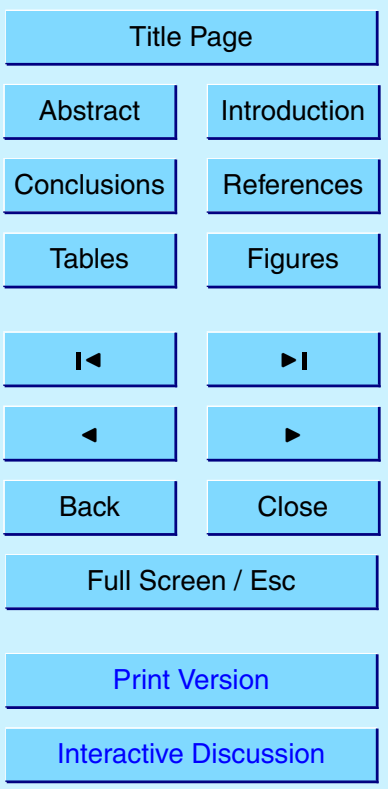

(C) EGU 2004 
tical analysis was developed and used in this paper. It can be used with operational vertical profiling measurements (e.g. radiosoundings, commercial aircraft or meteorological mast measurements, NWP data) or results of special field campaigns and urban boundary layer experimental studies.

For description of the urban $\mathrm{MH}$ structure the diagnostic parameterisation methods, based on surface data only, are not completely suitable due to the strong heterogeneities of UBL. It is necessary to utilise additional information about the vertical structure, temporal, and spatial variabilities of $\mathrm{MH}$. Therefore, the considered diagnostic methods for the MH estimation, based on operational vertical profile data available

10 (e.g. radiosoundings or AMDAR data), are recommended for practical usage (as a first approximation) together with more sophisticated prognostic equations with advection terms (e.g. Gryning and Batchvarova, 2001; Zilitinkevich and Baklanov, 2002). This approach can give a possibility to reconstruct the 3-D spatial and temporal structure of the urban $\mathrm{MH}$.

\section{Study results and methods comparison for urban and rural sectors}

Radiosounding data (during year of 2001) from the Jægersborg station were used as a basis for the study. Average annual vertical profiles for wind speed and potential temperature separately, during cases with the convective boundary layer and stable boundary layer, are presented in Fig. 2 . The shown statistics were considered separately for wind directions from 3 different sectors: (i) under urban influence (black squares), (ii) under sea/forest influence (red squares), and (iii) under rural influence (yellow triangles).

As one can see from the CBL graphics the wind velocity over the city and rural areas are similar on levels of hundred meters, but on the lowest levels the wind velocity in urban areas is lower (which can be naturally explained by the urban canopy effect). For the winds from the sea sector the velocities are considerably lower in general and characterised by a velocity minimum on the elevation of about $500 \mathrm{~m}$. This minimum

ACPD

4, 2839-2866, 2004

Mixing height for Copenhagen

A. Baklanov and

A. Kuchin

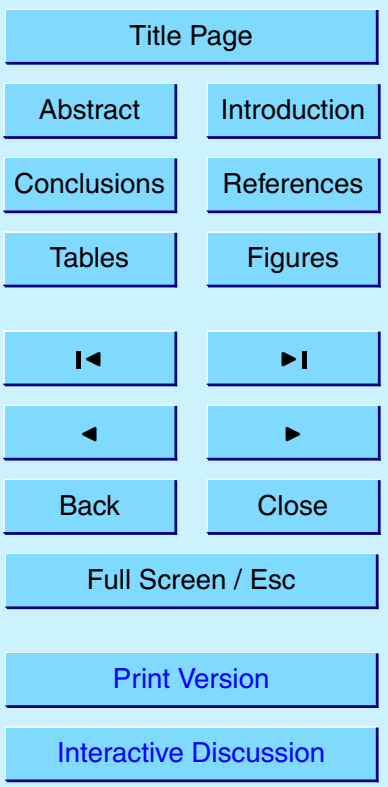

(C) EGU 2004 
corresponds to the average level of the breeze wind direction change. The average potential temperatures for urban area are higher than the temperatures in the rural areas on $1-2^{\circ}$ and about $5^{\circ}$ higher than in the sea sector. The vertical profile of temperature in lowest levels is characterised by a highest gradient in the urban sector.

$5 \quad$ For the SBL cases the situation differs considerably. The average wind velocity from the city sector is considerably higher compared with the rural areas. Of course, it is mostly explained not by the urban effects, but by the specific synoptic situations and characteristics of the northern and southern winds in the area. The potential temperature over the city and rural areas on levels higher than $700 \mathrm{~m}$ does not differ consid10 erably, but on the lowest levels the temperature is lower in urban areas. For the sea sector winds the velocity is also considerably lower than the winds from the urban sector (from $1.5 \mathrm{~m} / \mathrm{s}$ at $2 \mathrm{~m}$ level and up to $4 \mathrm{~m} / \mathrm{s}$ at levels higher than $600 \mathrm{~m}$ ) and from the rural sector (1-2 m/s). However, a velocity minimum is not very visible, it is possible to consider two local minima at elevations of about $200 \mathrm{~m}$ and at $500 \mathrm{~m}$. The first mini15 mum, most probably, corresponds to the average level of the wind direction change for nocturnal breezes. Note, the surface inversion in the urban area (sector) is not less than in the rural sector; and the elevated inversion (typical for the southern large cities) is not typical for the Copenhagen area (at least for the considered urban sector). These results support the hypothesis that in the Northern European cities the nocturnal SBL 20 is very common, and their UBL structure differs from the USA cities (see Bornstein, 2001; Baklanov, 2002).

Figure 3 gives similar information for meteorological profiles averaged for the winter period. For the SBL statistics the situation is similar on an annual scale, but the wind velocities in urban and rural areas are increased, and for the sea sector winds 25 the velocity has a visible velocity minimum at an elevation of about $200 \mathrm{~m}$ (which is responsible for the nocturnal breeze). Other important difference is that the potential temperature at the lowest levels in urban areas is higher compared with rural areas, and (most important) the surface inversions in urban areas are moderated than in the rural areas. Probably, the urban heat flux (including the anthropogenic and storage heat
ACPD

4, 2839-2866, 2004

Mixing height for Copenhagen

A. Baklanov and

A. Kuchin

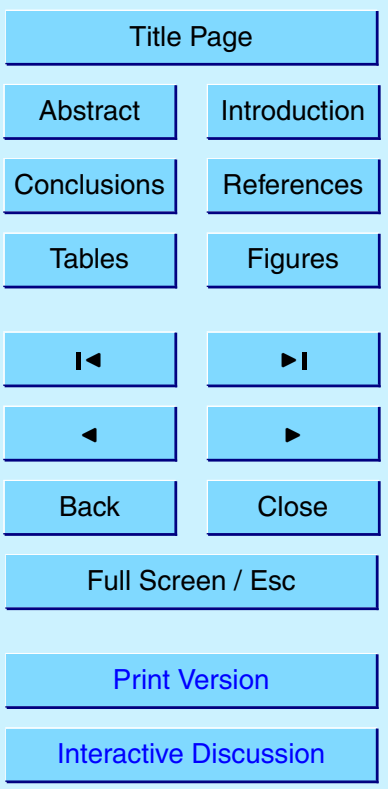

(c) EGU 2004 
fluxes) plays a more important role in the nocturnal UBL during winter seasons. For the CBL statistics, the wind velocities from the urban areas are relatively decreased, and from the sea sector - increased.

Let us consider results of the $\mathrm{MH}$ estimation from the above mentioned radiosound5 ing data for three sectors. Diagnostic methods were considered only, because the measurements were made only twice per day. As it was mentioned in Sect. 3, the following methods for the $\mathrm{MH}$ estimation were tested. For the CBL cases (mostly daytime measurements): the bulk Richardson number method (RI), the simple Parcel method (PAR), advance simple Parcel method (PARADV), the humidity jump method (HJMP) and the 10 experimental method of Benkley and Schulman (1979)(BS). For the SBL cases (nocturnal measurements in majority): the bulk Richardson number method (RI), the maximum low-level jet velocity method (VMAX), the humidity jump method (HJMP) and several parameterisation methods from Table 1, particularly, the method of Arya (1981)(AR81) and the experimental method of Benkley and Schulman (1979)(BS).

15 Separate analysis for the CBL and SBL cases was considered. Table 2 presents the results of the $\mathrm{MH}$ estimation for $\mathrm{SBL}$ over the Copenhagen area: mean value (in meters) and standard deviation of MHs, determined with the RI, AR81, BS, VMAX, and HJMP methods, and number of profiles $(\mathrm{N})$ for different sectors: (i) urban, (ii) semiurban and rural, (iii) water and coastal forest. It is visible from the Table, that the effect of the urban areas on the $\mathrm{MH}$ values is significant by all considered different methods (for 3 sectors). The average values of urban sector $\mathrm{MH}$ are higher than rural one on $102 \mathrm{~m}$ in average between the methods used. The average $\mathrm{MH}$ values for the water sector are also considerably lower than the urban $\mathrm{MH}$ on $135 \mathrm{~m}$ in average. Between the considered methods the bulk Richardson number method gives the lowest values of $\mathrm{MH}$ in urban/rural areas $(261 / 189 \mathrm{~m})$. Of course, without direct measurements of $\mathrm{MH}$ we can not make any conclusion about the correct values of $\mathrm{MH}$. However, based on our previous analysis of the bulk Richardson number method and comparison with direct $\mathrm{MH}$ measurements by Sodar (Zilitinkevich and Baklanov, 2002), it is expected that this method can underestimate the $\mathrm{MH}$ for SBL due to the fact that the critical value of

ACPD

4, 2839-2866, 2004

Mixing height for Copenhagen

A. Baklanov and A. Kuchin

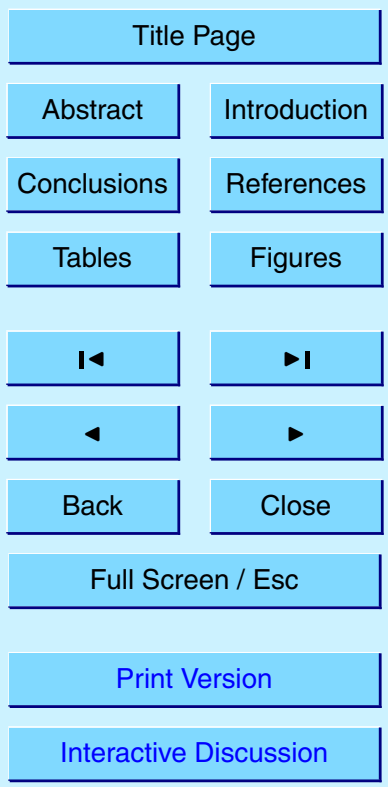

(c) EGU 2004 
the Ri-number is not a constant. It could be corrected by the improved method, suggested by Zilitinkevich and Baklanov (2002), considering the critical value as a function. Two other methods (AR81 and BS), based on the surface level measurements only, probably strongly overestimate the urban $\mathrm{MH}(783$ and $764 \mathrm{~m})$. The VMAX method 5 gives relatively realistic results. The HJMP method shows unexpectively reasonable results. However, it is not recommended to use this method, because it is usually used only for neutral and convective conditions. Probably, it is a reason that only this method didn't show the increasing of $\mathrm{MH}$ for the urban sector.

Figure 4 presents scatter plot diagrams of $\mathrm{MH}$ by the methods for the cases of SBL 10 over the Copenhagen area for the sectors. As one can see from the scatter plots, in general, the spreading of estimated $\mathrm{MH}$ values for the $\mathrm{SBL}$ cases is very high. The correlation coefficients, presented in Table 4, show that the correlation between the Rimethod and AR81 and BS methods is lower for the urban and water sectors compared with the rural sector. Main reason of this fact can be in effects of the internal boundary 15 layers due to the coast line or urban canopy. The correlation of VMAX and HJMP with other methods almost does not exist.

Table 2 presents the results of the $\mathrm{MH}$ estimation for the convective or neutral BL: mean value and standard deviation of $\mathrm{MHs}$, determined with the Richardson method (RI), Parcel method (PAR), advance Parcel method (PARADV) and humidity-jump method (HJMP), and number of profiles $(\mathrm{N})$ for different sectors: (i) urban, (ii) semiurban and rural, (iii) water and coastal forest.

In comparison with the SBL cases, where urban effects were significant, we can not see any considerable effect of the urban areas on the $\mathrm{MH}$ values for the $\mathrm{CBL}$ cases. The $\mathrm{MH}$ values are similar for the urban and rural sectors. In some cases we can

see the opposite effect where $\mathrm{MH}$ in water or rural sectors is higher than in the urban sector. This, from a first look unexpected, result is very natural for the Copenhagen metropolitan area due to its coastal position from several directions (see Fig. 1). For convective conditions the anthropogenic heat flux doesn't play a dominating role and the roughness features effect mainly. Therefore, an interaction of the breeze and urban
ACPD

4, 2839-2866, 2004

Mixing height for Copenhagen

A. Baklanov and

A. Kuchin

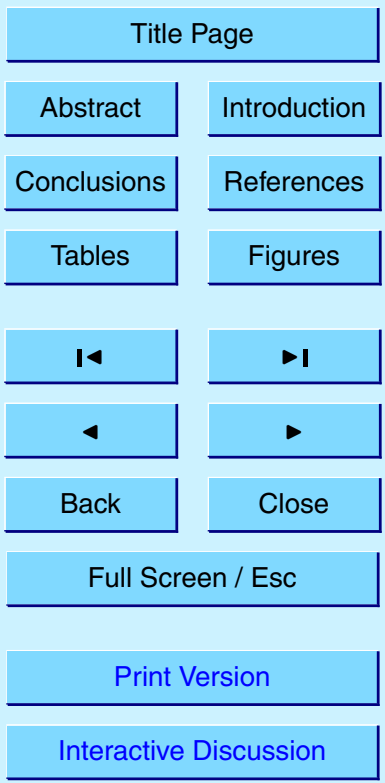

(C) EGU 2004 
effects and a combination of internal boundary layers form/effect on $\mathrm{MH}$ in CBL conditions over Copenhagen. So, the breeze effects, which are important not only for the water sector, but for the rural sector as well (see Fig. 1), are stronger for CBL cases when the urban effects. Therefore, it is reasonable that $\mathrm{MHs}$ from the rural and water 5 sectors are similar or slightly higher compared with the urban sector.

It is necessary to stress that the values of $\mathrm{MH}$ for $\mathrm{CBL}$ in all sectors are relatively similar: RI - $887 \mathrm{~m}$, BS $-860 \mathrm{~m}$, PAR $-812 \mathrm{~m}$, and PARADV - $1032 \mathrm{~m}$. Only the HJMP method gives the lower $\mathrm{MH}$ value $-582 \mathrm{~m}$, however the number of cases, where this method was applicable, was much lower (59/169), therefore, it can not be considered 10 as statistically correct for the inter-comparisons. Table 5 presents the correlation coefficients between the methods of $\mathrm{MH}$ estimation for $\mathrm{CBL}$. It is visible that most of the methods show very good correlations for all three sectors. The RI, PAR and PARADV methods have correlation coefficients from 0.90 up to 0.97 . The exceptions are the BS and HJMP methods with very low correlation coefficients. It is not surprising, because

the Benkley-Schulman method, using $10 \mathrm{~m}$ velocity as the only criterion, was not developed for the convective conditions (we considered it just for a simple test of applicability of such simple methods). The HJMP method shows reasonable results, but it is not a stable method, because of many cases where the method is not applicable (see the number of measurements considered).

Figure 5 presents the scatter plot diagrams of the $\mathrm{MH}$ calculation by different methods for the cases of CBL over the Copenhagen area for three main sectors. As one can see from the scatter plots, in general, the spreading of estimated $\mathrm{MH}$ values for the SBL cases is relatively low for the RI, PAR and PARADV methods. The scatter plots for the BS and HJMP methods vs. other methods showed a very high spreading of data 25 and almost no correlations. Therefore, the BS and HJMP methods can not be recommended for practical usage. To minimise the uncertainties, it is recommended to use a combination of the $\mathrm{RI}$ and Parcel methods for diagnosis of $\mathrm{MH}$ from radiosounding profiles for urban and non-urban conditions of CBL.

Additionally, the analysis of the considered data and $\mathrm{MH}$ estimations showed, that
ACPD

4, 2839-2866, 2004

Mixing height for Copenhagen

A. Baklanov and A. Kuchin

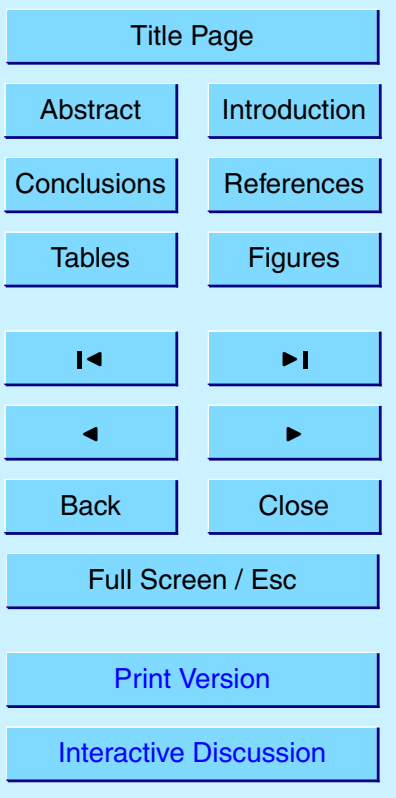

(C) EGU 2004 
there is a time delay $(\sim 2-3 \mathrm{~h})$ for the $\mathrm{MH}$ formation over water surface (from the water sector) compared with the rural and urban MHs. However, for deeper studies of this effect it is necessary to employ more frequent measurements or to consider additionally results of the high-resolution meteorological modelling in the study area and 5 surroundings.

It is necessary to mention that the selection of different criteria for the sector choose is very important. Especially it is important for the water sector data due to the effect of the breeze circulation. Figure 6 shows the scatter plots for the water sector data, chosen by the wind direction on the first measurement level or at the height of $500 \mathrm{~m}$.

10 As we can see, the number of measurements are very different, because the wind direction is changed due to the breeze circulation: during daytime - within $500-800 \mathrm{~m}$, and during night-time at $\sim 200 \mathrm{~m}$.

\section{Conclusions and recommendations}

The UBL can be considered as a specific case of ABL over a non-homogeneous terrain. 15 It is related, first of all, to abrupt changes of the surface roughness and urban surface heat fluxes.

Based on the year of 2001 statistics for the radiosounding vertical profiles from the Jægersborg station (Copenhagen, Denmark), the urban features for the Greater Copenhagen area effecting the $\mathrm{MH}$ and differences between urban and rural $\mathrm{MHs}$ were

analysed. It was shown that the urban $\mathrm{MH}$ is considerably higher for the stably stratified (nocturnal) boundary layer cases in comparison with the "non-urban" MH. Daytime (usually CBL) MH does not differ significatly in urban and "non-urban" sectors. For convective conditions the anthropogenic heat flux doesn't play a dominating role and the roughness features effect mainly. Therefore, an interaction of the sea breeze and urban effects and a combination of internal boundary layers forms the $\mathrm{MH}$ in $\mathrm{CBL}$ conditions over Copenhagen.

Based on the considered data and diagnostic method analysis, general suggestions,

ACPD

4, 2839-2866, 2004

Mixing height for Copenhagen

A. Baklanov and A. Kuchin

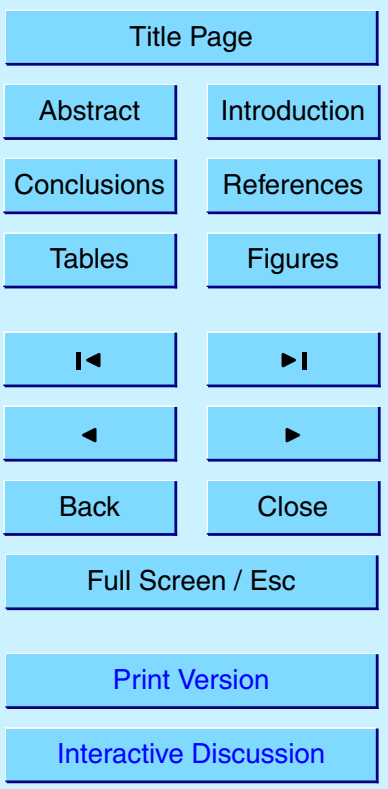

(c) EGU 2004 
concerning an applicability of "rural" methods of the MH estimation for urban areas, are the following.

Radiosonde routine measurements can be used for estimation of $\mathrm{MH}$ in urbanised areas due situations of such stations close to large growing cities, increasing vertical 5 resolution of modern measurements and operational access to data.

For estimation of the daytime $\mathrm{MH}$, the applicability of common methods (Seibert et al., 1998) is more acceptable than for the nocturnal $\mathrm{MH}$. To minimise the uncertainties, a combination of the $\mathrm{RI}$ and Parcel methods for diagnosis of $\mathrm{MH}$ from radiosounding profiles for urban and non-urban conditions of CBL can be recommended.

10 The formation of the nocturnal UBL occurs in a counteraction with the negative "nonurban" surface heat fluxes and positive anthropogenic/urban heat fluxes, and hence, the applicability of common methods for the SBL estimation is less promising.

Meso-meteorological and NWP models with modern high-order non-local turbulence closures give promising results (especially, for $\mathrm{CBL}$ ). However, currently the urban ef15 fects in such models are not included or included with great simplifications (Baklanov et al., 2002). Therefore, it is very important to test different MH schemes not specifically designed for the urban environment against the urban $\mathrm{MH}$ or IBL schemes for different datasets (first of all for nocturnal conditions) from different urban sites to gain insight in possible improvements.

20 For description of the urban $\mathrm{MH}$ structure the diagnostic parameterisation methods, based on surface data only, are not completely suitable due to the strong heterogeneities of the UBL. It is necessary to utilise additional information about the vertical structure, temporal and spatial variabilities of $\mathrm{MH}$. Therefore, the considered diagnostic methods for the $\mathrm{MH}$ estimation, based on operational vertical profile data available 25 (e.g. radiosounding or AMDAR data), can be recommended for practical usage (as a first approximation) together with prognostic equations with advection terms (e.g. Gryning and Batchvarova, 2001; Zilitinkevich and Baklanov, 2002). This approach gives a possibility to reconstruct the 3-D spatial and temporal structure of the urban $\mathrm{MH}$.

Acknowledgements. The authors are very grateful to A. Rasmussen and N. Jepsen (DMI) for

Mixing height for Copenhagen

A. Baklanov and A. Kuchin

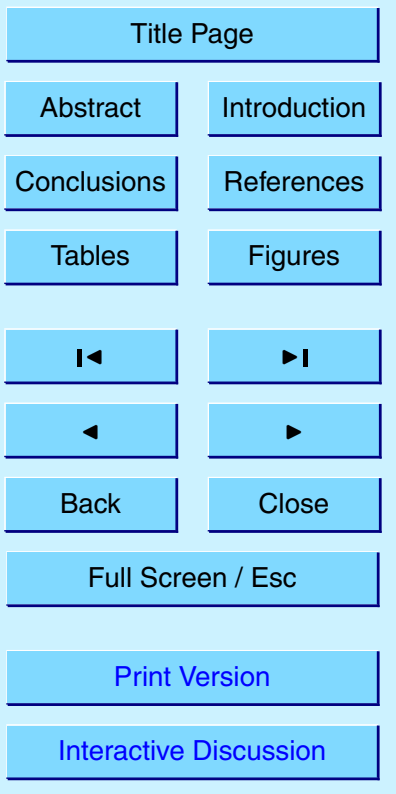

(c) EGU 2004 
very useful discussions and help with preparation of the radiosounding dataset. This work was realised in the bounds of the co-operation within WG2 COST Action 715 and the 5FP EC project FUMAPEX. The paper was presented on the "Urban meteorology and atmospheric pollution"

Section of the Joint EGS-AGU-EUG Assembly, Nice, France, April 2003.

\section{References}

AMDAR: International AMDAR Program: Aircraft Meteorological Data Relay, WMO, AMDAR Panel, 7, 2003.

Arya, S. P. S.: Parameterizing the height of the stable atmospheric boundary layer, J. Appl. Meteorol. 20, 1192-1202, 1981.

Baklanov, A.: Parameterisation of SBL height in atmospheric pollution models, Air Pollution Modelling and its Application XV, edited by Borrego, C. and Schayes, G., NATO/CCMS ITM2001, Kluwer Academic/Plenum Publishers, 415-424, 2001.

Baklanov, A.: The mixing height in urban areas - a review, Mixing heights and inversions in urban areas, edited by Piringer, M. and Kukkonen, J., COST Action 715: Urban Meteorology,

15 EC Publication EUR 20451, 9-28, 2002.

Baklanov, A., Rasmussen, A., Fay, B., Berge, E., and Finardi, S.: Potential and shortcomings of NWP models in providing meteorological dat for UAP forecasting, Water, Air and Soil Poll.: Focus, 2, (5-6), 43-60, 2002.

Benkley, C. W. and Schulman, L. L.: Estimating mixing depths from historical meteorological data, J. Appl. Meteorol, 18, 772-780, 1979.

Bornstein, R. D.: Currently used parameterisations in numerical models, Workshop on Urban Boundary Layer Parameterisations, COST 715, Zürich, 24-25 May 2001, 2001.

E-AMDAR: EUMETNET-AMDAR Project: Aircraft Meteorological Data Reporting, http://www. metoffice.com/research/interproj/amdar/index.html, 2002.

25 Fisher B. E. A., Kukkonen, J., and Schatzmann, M.: Meteorology applied to urban air pollution problems COST 715, Int. J. Envir. and Poll., 16, 560-569, 2001.

Gryning, S.-E. and Batchvarova, E.: Mixing height in urban areas: will "rural" parameterisations work?, COST-Action 715 Workshop on Urban Boundary Layer Parameterisations, Zürich, 24-25 May 2001, 10, 2001.

Mixing height for Copenhagen

A. Baklanov and A. Kuchin

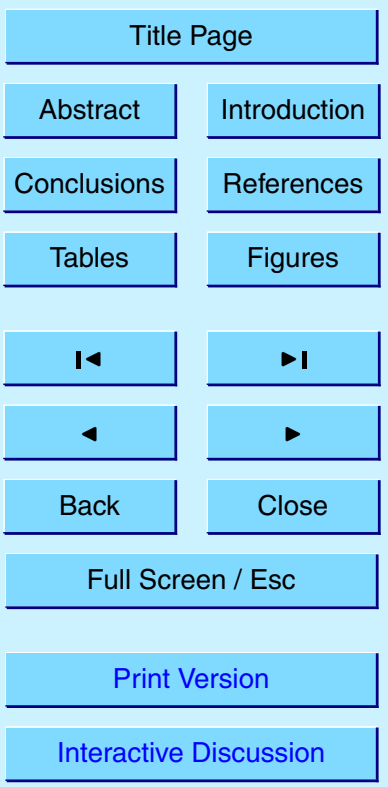

(c) EGU 2004 
Lena, F. and Desiato, F.: Intercomparison of nocturnal mixing height estimate methods for urban air pollution modelling, Atmos. Environ., 33, (15), 2385-2393, 1999.

Mestayer, P. G., Durand, P., Augustin, P., et al.: UBL/CLU-ESCOMPTE: The urban boundary layer field experiment over Marseille \& data base, Urban Air Quality: Measurement, Mod-

$5 \quad$ elling and Management, Prague, Czech Republic, 24-27 March 2001, 2003.

Piringer, M., Grimmond, C. S. B., Joffre, S. M., Mestayer, P., Middleton, D. R., Rotach, M. W., Baklanov, A., De Ridder, K., Ferreira, J., Guilloteau, E., Karppinen, A., Martilli, A., Masson, V., and Tombrou, M.: Investigating the Surface Energy Balance in Urban Areas - Recent Advances and Future Needs, Water, Air and Soil Poll.: Focus, 2, (5-6), 1-16, 2002.

Rotach, M. W., Mitev, V., and Vogt, R.: BUBBLE - current status of the experiment and planned investigations/evaluations of the mixing height, Mixing heights and inversions in urban areas, edited by Piringer, M. and Kukkonen, J., COST Action 715: Urban Meteorology, EC Publication EUR 20451, 45-52, 2002.

Seibert, P., Beyrich, F., Gryning, S.-E., Joffre, S., Rassmussen, A., and Tercier, Ph.: Mixing 15 Height Determination for Dispersion Modelling, Report of Working group 2. COST Action 710, edited by Fisher, B. E. A., Erbrink, J. J., Finardi, S., et al., in: Preprocessing of Meteorological data for Dispersion Modelling, May 1997, 1998.

Zilitinkevich, S., Baklanov, A., Rost, J., Smedman, A.-S., Lykosov, V., and Calanca, P.: Diagnostic and prognostic equations for the depth of the stably stratified Ekman boundary layer, Quarterly Journal of the Royal Meteorological Society, 128, 25-46, 2002.

Zilitinkevich, S. and Baklanov, A.: Calculation of the height of stable boundary layers in practical applications, Boundary-Layer Meteorology, 105, (3), 389-409, 2002.

Mixing height for Copenhagen

A. Baklanov and A. Kuchin

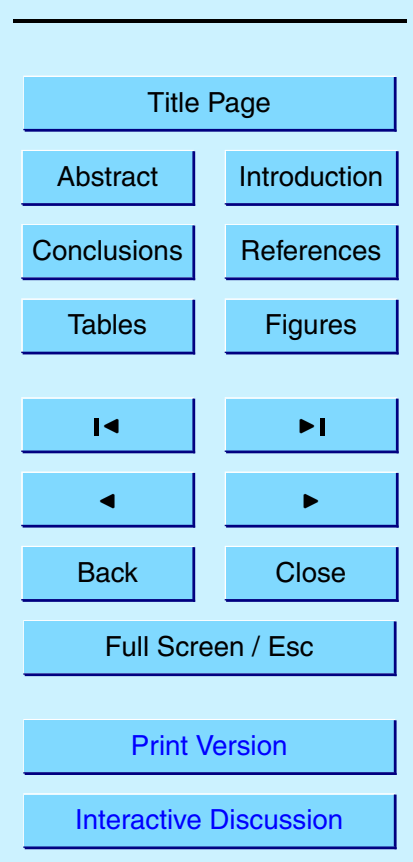

(c) EGU 2004 


\section{ACPD}

Table 1. Empirical evaluation of different SBL height equations, where the friction velocity $u_{*}$, the buoyancy flux $B_{s}$, the Monin-Obukhov length $L$, the Coriolis parameter $f$, the 10-m-wind $u_{10}$, and the Brunt-Väisälä frequency $N$ (after Zilitinkevich and Baklanov, 2002).

\begin{tabular}{lllccc}
\hline$\#$ & Reference & SBL height equation & Bias & $\begin{array}{c}\text { RMS } \\
\text { error }\end{array}$ & $\begin{array}{c}\text { Correlation } \\
\text { coefficient }\end{array}$ \\
\hline 1 & Aria, 1981* & $h=0.42 u_{*}^{2}\left|f B_{s}\right|^{-1 / 2}+29.3$ & 64.0 & 218 & 0.27 \\
\hline 2 & Niewstadt, 1984 & $h=0.4 u_{*}^{2}\left|f B_{s}\right|^{-1 / 2}$ & 24.4 & 173 & 0.27 \\
\hline 3 & Arya, 1981 & $h=0.089 u_{*} /|f|+85.1$ & 103 & 86.3 & 0.48 \\
\hline 4 & Mahrt, 1982 & $h=0.06 u_{*} /|f|$ & -24.4 & 18 & 0.48 \\
\hline 5 & $\begin{array}{l}\text { Benkley and } \\
\text { Schulman, 1979 }\end{array}$ & $h=125 u_{10}$ & 208 & 264 & 0.48 \\
\hline 6 & Niewstadt, 1984 & $h=28 u_{10}^{3 / 2}$ & 6.27 & 13.9 & 0.48 \\
\hline 7 & $\begin{array}{l}\text { Zilitinkevich and } \\
\text { Mironov, 1996 }\end{array}$ & $\left(\frac{f h}{0.5 u_{*}}\right)^{2}+\frac{h}{10 L}+\frac{N h}{20 u_{*}}+\frac{h|f|^{1 / 2}}{\left(u_{*} L\right)^{1 / 2}}+\frac{h|N f|^{1 / 2}}{1.7 u_{*}}=1$ & -33.8 & 33.8 & 0.38 \\
\hline 8 & $\begin{array}{l}\text { Zilitinkevich } \\
\text { et al., 2002 }\end{array}$ & $h=\frac{0.4 u_{*}}{|f|}\left[\left(1+0.3 \frac{w_{h}}{u_{*}}\right) /\left(1+\frac{0.16 u_{*}\left(1+0.25 N L / u_{*}\right)}{0.55 L|f|}\right)\right]^{1 / 2}$ & 6.21 & 19.2 & 0.60 \\
\hline
\end{tabular}

4, 2839-2866, 2004

Mixing height for Copenhagen

A. Baklanov and A. Kuchin

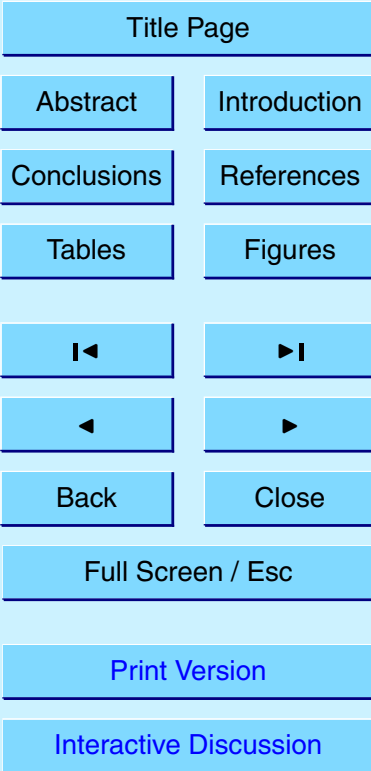

*Version modified after Zilitinkevich (1972) with re-estimated constants.

Interactive Discussion

(C) EGU 2004 


\section{ACPD}

Table 2. Stably stratified BL over the Copenhagen area: mean value (in meters) and standard deviation of MHs, determined with bulk Richardson method (RI), Arya (1981) method (AR81), Benkley-Schulman method (BS), maximum low-level jet velocity method (VMAX) and humidityjump method (HJMP), and number of profiles $(\mathrm{N})$ for different sectors: (i) urban, (ii) semi-urban and rural, (iii) water and coastal forest.

\begin{tabular}{llrrrrr}
\hline SECTOR & & RI & AR81 & BS & VMAX & HJMP \\
\hline Water (iii) & Mean & 173 & 350 & 475 & 552 & 633 \\
& N & 42 & 42 & 42 & 42 & 10 \\
& Std. Deviation & 199 & 177 & 318 & 204 & 270 \\
\hline \multirow{2}{*}{ Urban (i) } & Mean & 261 & 783 & 764 & 593 & 456 \\
& N & 114 & 114 & 114 & 114 & 44 \\
& Std. Deviation & 197 & 433 & 474 & 192 & 260 \\
\hline \multirow{2}{*}{ Rural (ii) } & Mean & 189 & 451 & 595 & 552 & 462 \\
& N & 122 & 122 & 121 & 122 & 59 \\
& Std. Deviation & 175 & 255 & 410 & 199 & 260 \\
\hline Total & Mean & 216 & 572 & 646 & 569 & 475 \\
& N & 278 & 278 & 277 & 278 & 113 \\
& Std. Deviation & 191 & 377 & 437 & 197 & 263 \\
\hline
\end{tabular}

4, 2839-2866, 2004

Mixing height for Copenhagen

A. Baklanov and A. Kuchin

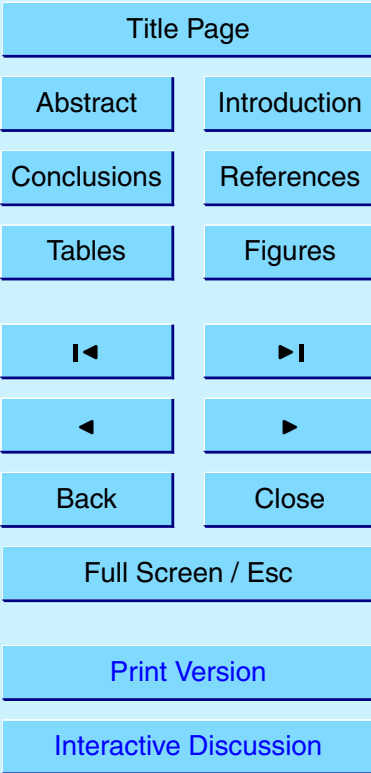

(C) EGU 2004 


\section{ACPD}

Table 3. Convective or neutral BL over the Copenhagen area: mean value (in meters) and standard deviation of MHs, determined with Richardson method (RI), Parcel method (PAR), advance Parcel method (PARADV) and humidity-jump method (HJMP), and number of profiles (N) for different sectors: (i) urban, (ii) semi-urban and rural, (iii) water and coastal forest.

\begin{tabular}{llrrrrr}
\hline SECTOR & & RI & BS & PAR & PARADV & HJMP \\
\hline \multirow{2}{*}{ Water (iii) } & Mean & 858 & 559 & 771 & 1038 & 624 \\
& N & 28 & 28 & 28 & 28 & 9 \\
& Std. Deviation & 362 & 285 & 410 & 390 & 291 \\
\hline \multirow{2}{*}{ Urban (i) } & Mean & 799 & 918 & 718 & 900 & 532 \\
& N & 61 & 61 & 61 & 61 & 29 \\
& Std. Deviation & 415 & 440 & 445 & 494 & 238 \\
\hline \multirow{2}{*}{ Rural (ii) } & Mean & 965 & 920 & 898 & 1130 & 634 \\
& N & 80 & 80 & 80 & 80 & 21 \\
& Std. Deviation & 368 & 387 & 403 & 403 & 255 \\
\hline Total & Mean & 887 & 860 & 812 & 1032 & 582 \\
& N & 169 & 169 & 169 & 169 & 59 \\
& Std. Deviation & 390 & 413 & 426 & 446 & 253 \\
\hline
\end{tabular}

4, 2839-2866, 2004

Mixing height for Copenhagen

A. Baklanov and

A. Kuchin

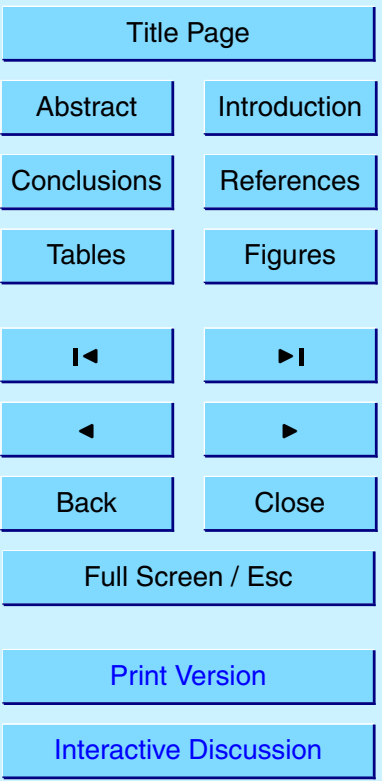

(C) EGU 2004 


\section{ACPD}

Table 4. Stably stratified BL over the Copenhagen area: correlation coefficients between methods of MH estimation: bulk Richardson method (RI), Arya (1981) method (AR81), BenkleySchulman method (BS), maximum low-level jet velocity method (VMAX), and humidity-jump method (HJMP) for different sectors: (i) urban, (ii) semi-urban and rural, (iii) water and coastal forest.

\begin{tabular}{llrrrrr}
\hline SECTOR & & RI & AR81 & BS & VMAX & HJMP \\
\hline Water (iii) & RI & 1.00 & 0.60 & 0.60 & 0.25 & 0.46 \\
& AR81 & 0.60 & 1.00 & 1.00 & 0.02 & 0.20 \\
& BS & 0.60 & 1.00 & 1.00 & 0.02 & 0.20 \\
& VMAX & 0.25 & 0.02 & 0.02 & 1.00 & 0.05 \\
& HJMP & 0.46 & 0.20 & 0.20 & 0.05 & 1.00 \\
\hline Urban (i) & RI & 1.00 & 0.62 & 0.62 & 0.31 & 0.17 \\
& AR81 & 0.62 & 1.00 & 1.00 & 0.38 & 0.32 \\
& BS & 0.62 & 1.00 & 1.00 & 0.38 & 0.32 \\
& VMAX & 0.31 & 0.38 & 0.38 & 1.00 & 0.48 \\
& HJMP & 0.17 & 0.32 & 0.32 & 0.48 & 1.00 \\
\hline Rural (ii) & RI & 1.00 & 0.80 & 0.80 & 0.13 & 0.23 \\
& AR81 & 0.80 & 1.00 & 1.00 & 0.18 & 0.31 \\
& BS & 0.80 & 1.00 & 1.00 & 0.20 & 0.31 \\
& VMAX & 0.13 & 0.18 & 0.20 & 1.00 & 0.01 \\
& HJMP & 0.23 & 0.31 & 0.31 & 0.01 & 1.00 \\
\hline
\end{tabular}

4, 2839-2866, 2004

Mixing height for Copenhagen

A. Baklanov and

A. Kuchin

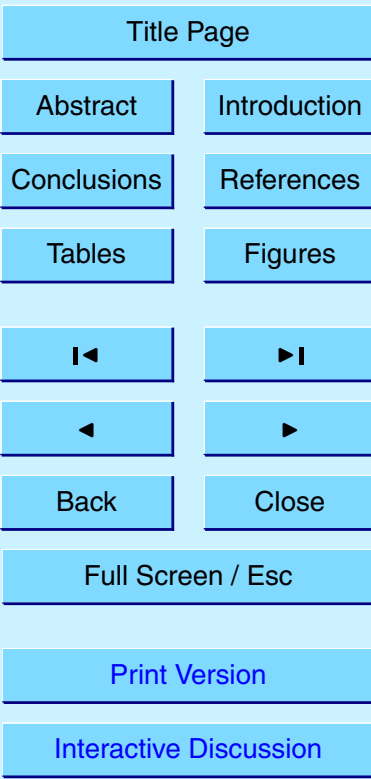

(C) EGU 2004 


\section{ACPD}

Table 5. Convective or neutral BL over the Copenhagen area: correlation coefficients between methods of $\mathrm{MH}$ estimation: bulk Richardson method (RI), Benkley-Schulman method (BS), Parcel method (PAR), advance Parcel method (PARADV), and humidity-jump method (HJMP) for different sectors: (i) urban, (ii) semi-urban and rural, (iii) water and coastal forest.

\begin{tabular}{llrrrrr}
\hline SECTOR & & RI & BS & PAR & PARADV & HJMP \\
\hline Water (iii) & RI & 1.00 & 0.12 & 0.94 & 0.90 & 0.26 \\
& BS & 0.12 & 1.00 & -0.02 & -0.02 & 0.81 \\
& PAR & 0.94 & -0.02 & 1.00 & 0.87 & 0.32 \\
& PARADV & 0.90 & -0.02 & 0.87 & 1.00 & -0.15 \\
& HJMP & 0.26 & 0.81 & 0.32 & -0.15 & 1.00 \\
\hline Urban (i) & RI & 1.00 & 0.20 & 0.97 & 0.97 & 0.49 \\
& BS & 0.20 & 1.00 & 0.12 & 0.15 & 0.10 \\
& PAR & 0.97 & 0.12 & 1.00 & 0.97 & 0.52 \\
& PARADV & 0.97 & 0.15 & 0.97 & 1.00 & 0.48 \\
& HJMP & 0.49 & 0.10 & 0.52 & 0.48 & 1.00 \\
\hline Rural (ii) & RI & 1.00 & 0.34 & 0.95 & 0.93 & 0.31 \\
& BS & 0.34 & 1.00 & 0.24 & 0.23 & 0.49 \\
& PAR & 0.95 & 0.24 & 1.00 & 0.92 & 0.24 \\
& PARADV & 0.93 & 0.23 & 0.92 & 1.00 & 0.28 \\
& HJMP & 0.31 & 0.49 & 0.24 & 0.28 & 1.00 \\
\hline
\end{tabular}

4, 2839-2866, 2004

Mixing height for Copenhagen

A. Baklanov and

A. Kuchin

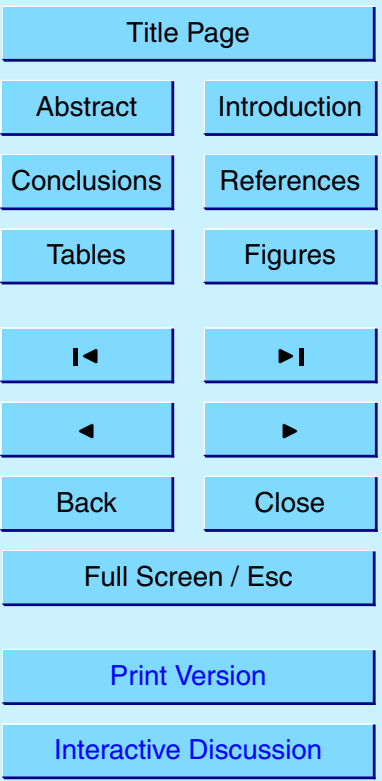

(C) EGU 2004 


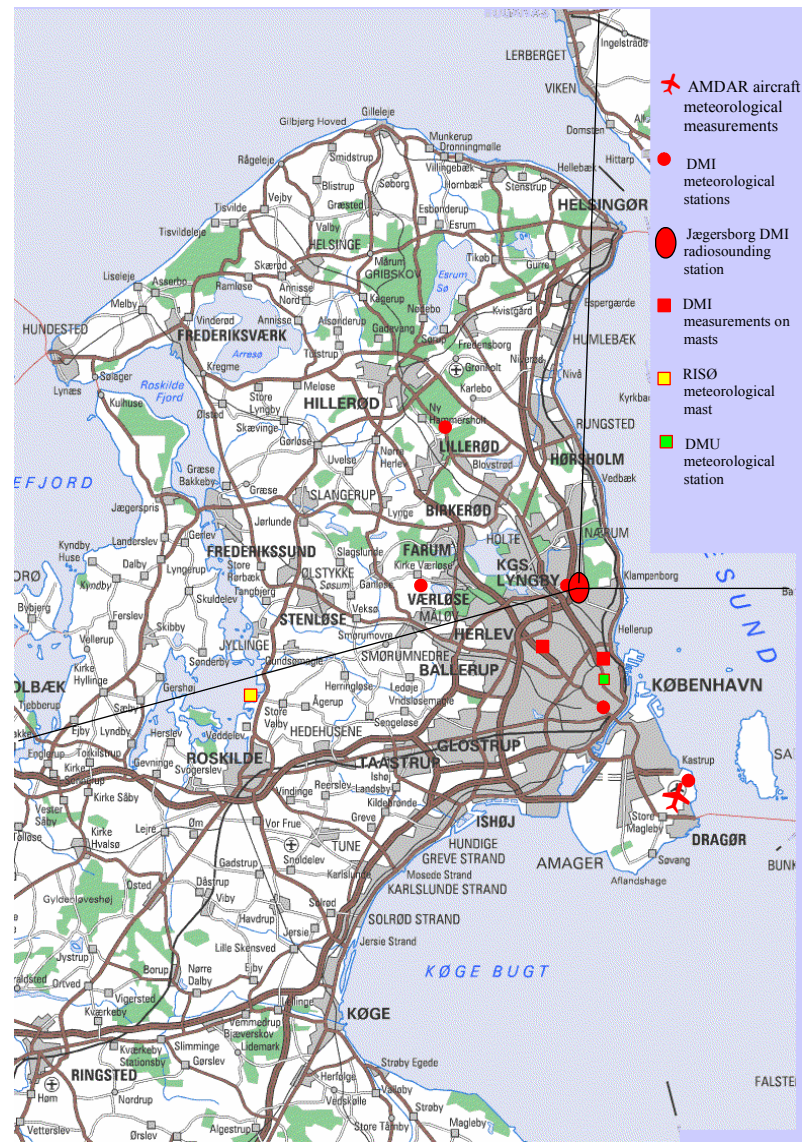

Fig. 1. Scheme of the Copenhagen Metropolitan area and surroundings with marked positions of meteorological measurement stations. The radiosounding station Jægersborg is marked by a big red ellipse, the corresponding 3 sectors, considered in the paper for the station, are separated by the black lines.

\section{ACPD}

4, 2839-2866, 2004

\section{Mixing height for} Copenhagen

A. Baklanov and A. Kuchin

Title Page

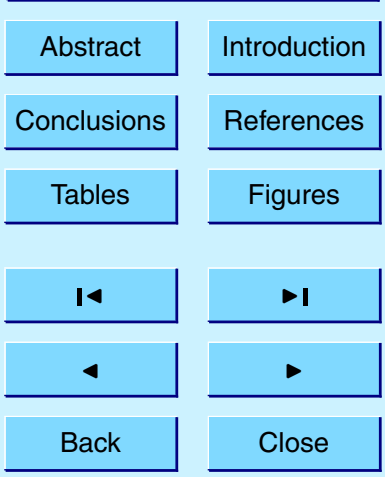

Full Screen / Esc

Print Version

Interactive Discussion

(C) EGU 2004 


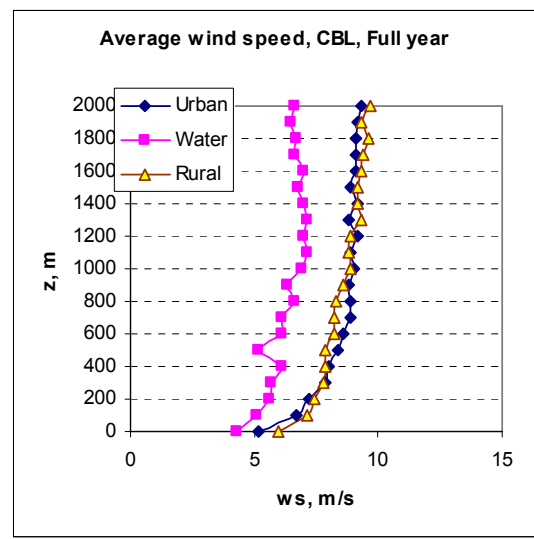

(a)

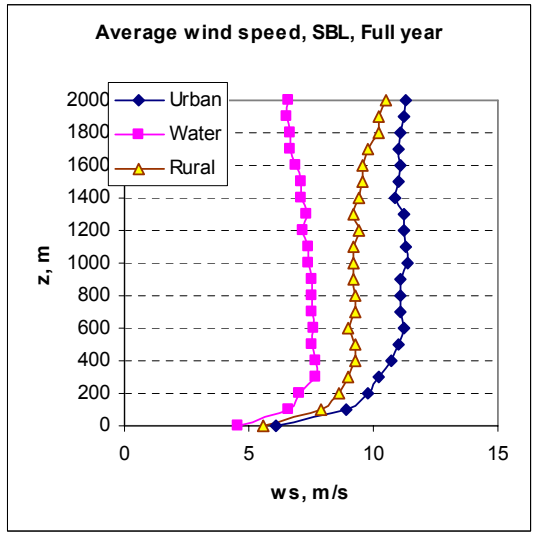

(c)

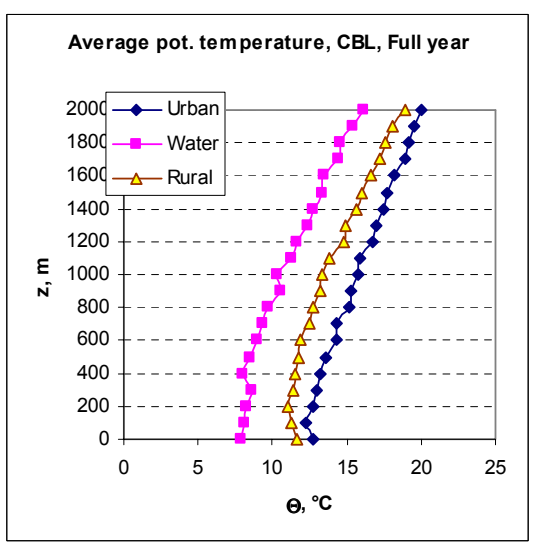

(b)

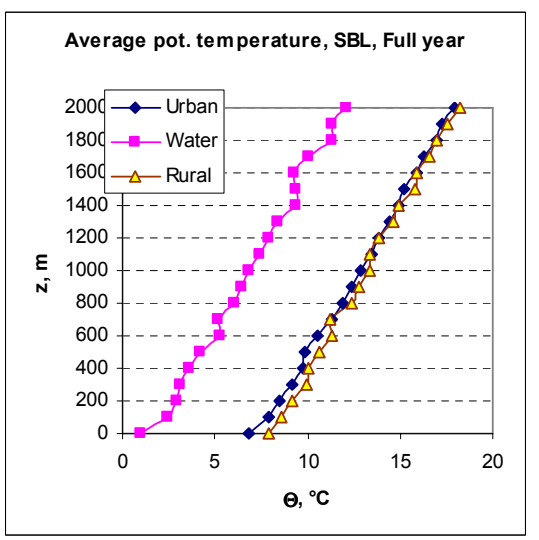

(d)

\section{ACPD}

4, 2839-2866, 2004

Mixing height for Copenhagen

A. Baklanov and

A. Kuchin

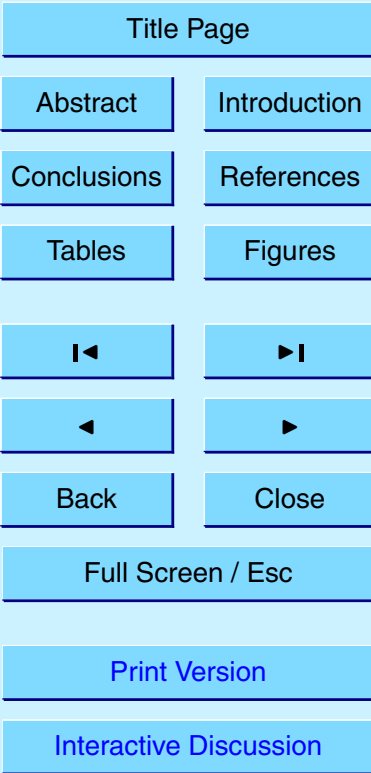

during cases with $\mathrm{CBL}(\mathrm{a}, \mathrm{b})$ and $\mathrm{SBL}(\mathrm{c}, \mathrm{d})$ at the Jægersborg station in Copenhagen for wind directions from different sectors: under urban influence (black squares), under sea/forest influence (red squares), and under rural influence (yellow triangles). 


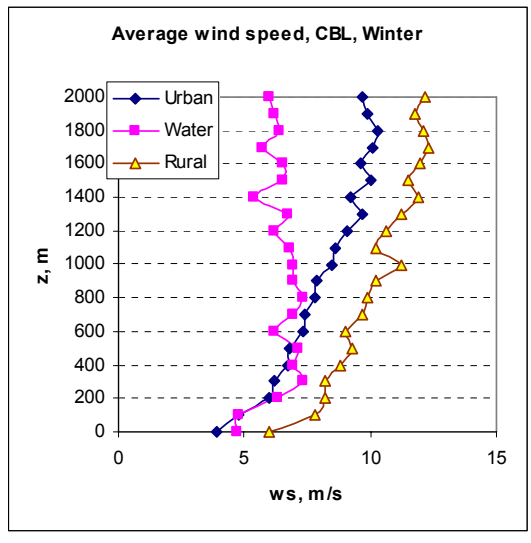

(a)

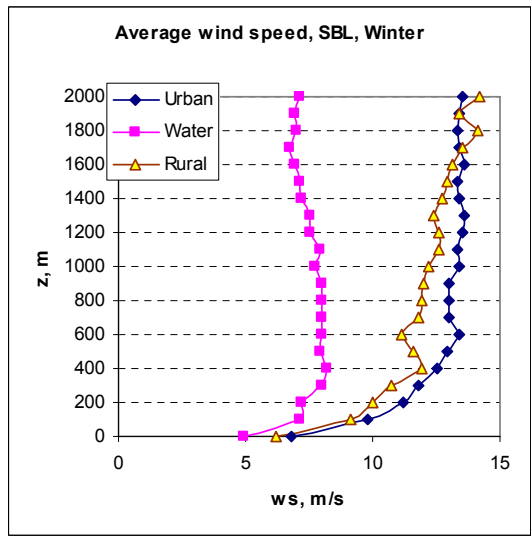

(c)

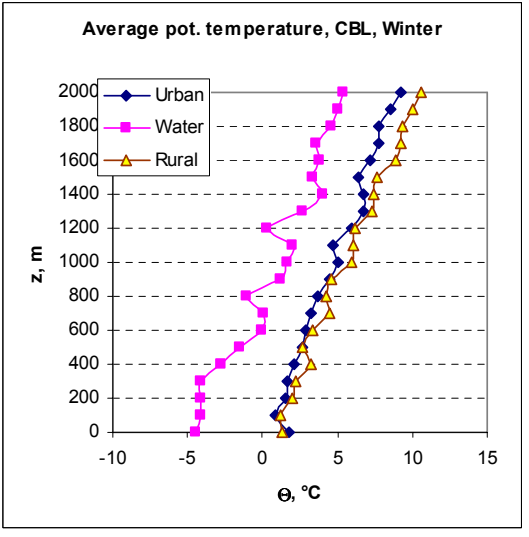

(b)

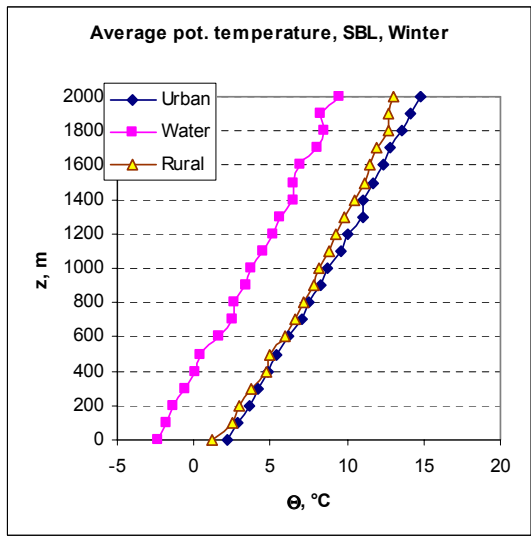

(d)

\section{ACPD}

4, 2839-2866, 2004

Mixing height for Copenhagen

A. Baklanov and

A. Kuchin

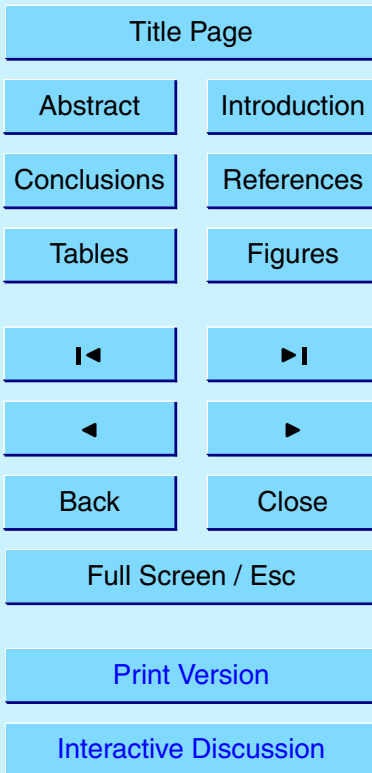

during cases with $\operatorname{CBL}(a, b)$ and $\operatorname{SBL}(c, d)$ at the Jægersborg station in Copenhagen for wind directions from different sectors: under urban influence (black squares), under sea/forest influence (red squares), and under rural influence (yellow triangles).

(C) EGU 2004 


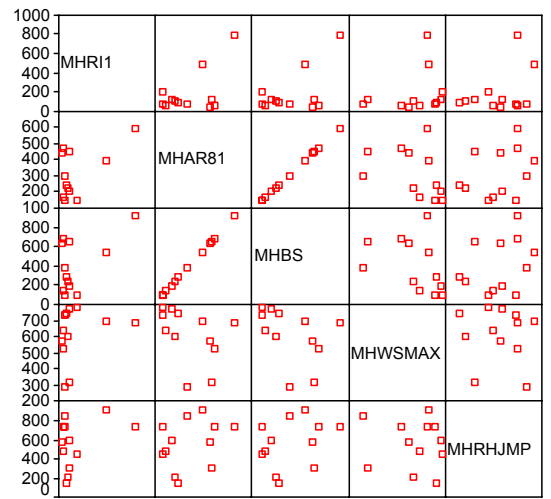

SURF: 2 Urban

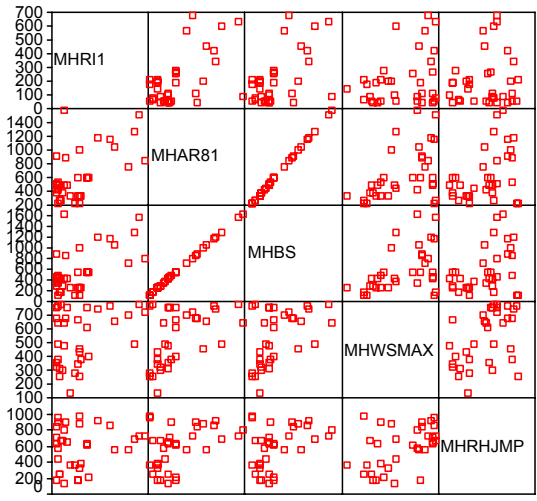

Fig. 4. Matrixes of scatter plots of the SBL MH calculated by different methods: bulk Richardson method (RI1), Arya (1981) method (AR81), Benkley-Schulman method (BS), maximum lowlevel jet velocity method (WSMAX), and humidity-jump method (RHJMP) from Jægersborg (Copenhagen) radio- sounding profiles for different sectors: (1) water and coastal forest, (2) urban, (3) semi-urban and rural.

\begin{abstract}
SURF: 3 Rura
\end{abstract}

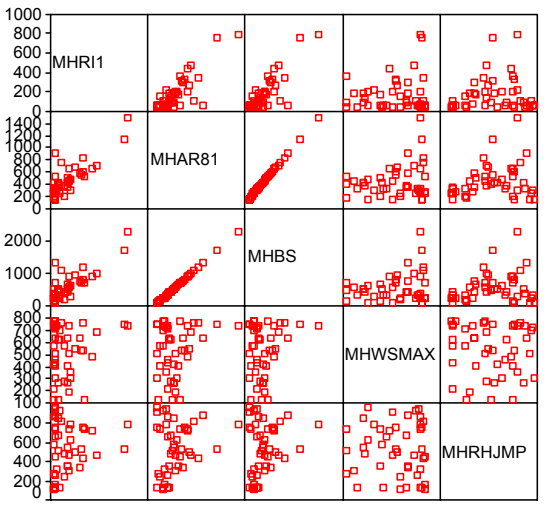

4, 2839-2866, 2004

Mixing height for Copenhagen

A. Baklanov and

A. Kuchin

Title Page

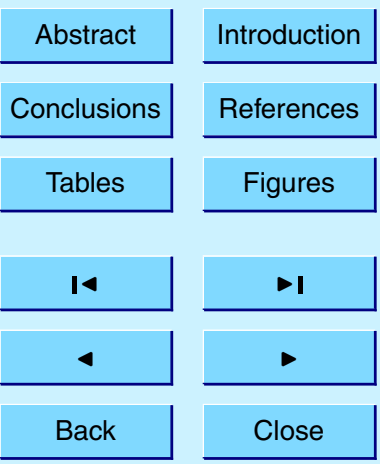

Full Screen / Esc

Print Version

Interactive Discussion

(C) EGU 2004 
SURF: 2 Urban

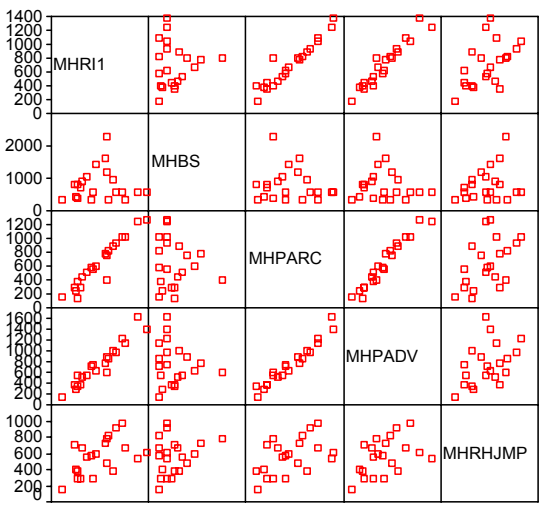

SURF: 3 Rural

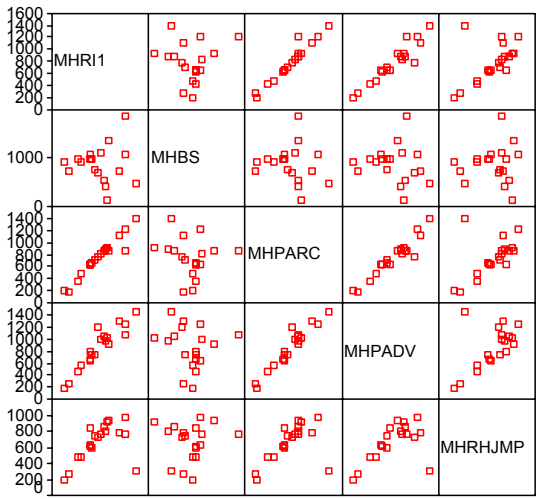

Fig. 5. Matrixes of scatter plots of the CBL MH calculated by different methods: bulk Richardson method (RI1), Benkley-Schulman method (BS), Parcel method (PARC), advance Parcel method (PADV), and humidity-jump method (RHJMP) from Jægersborg (Copenhagen) radiosounding profiles for different sectors: (1) water and coastal forest, (2) urban, (3) semi-urban and rural.

\section{Mixing height for} Copenhagen

A. Baklanov and

A. Kuchin

Title Page

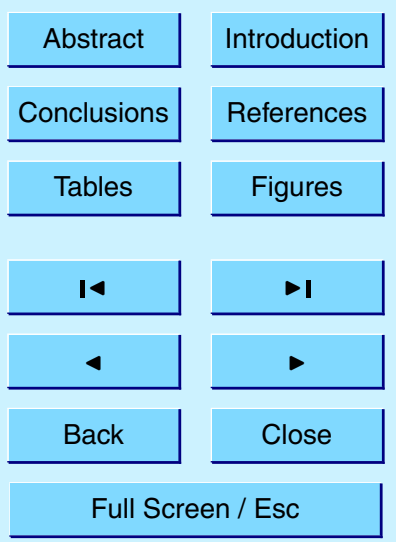

Print Version

Interactive Discussion

(C) EGU 2004 


\section{ACPD}

4, 2839-2866, 2004

Mixing height for

Copenhagen

SURF: 1 WATER

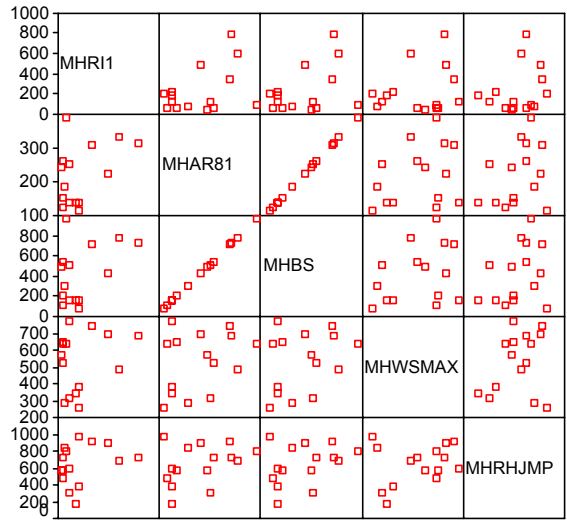

SBL
SURF: 1 WATER

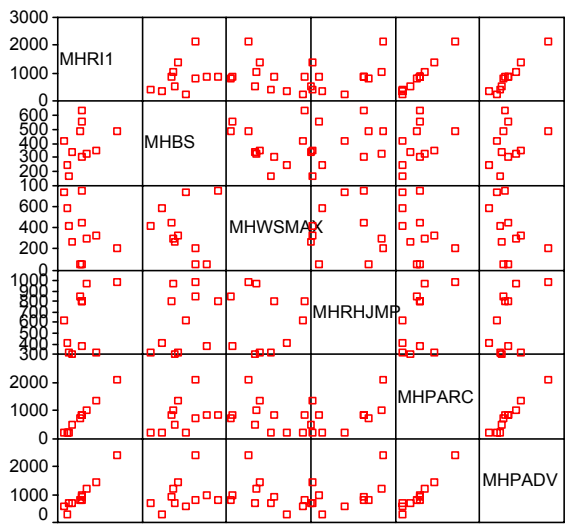

CBL

Fig. 6. Matrixes of scatter plots of the SBL (left) and CBL (right) $\mathrm{MH}$ calculated by different methods for the "semi-urban and rural" sector, in the case if it chosen by the wind direction on the first measurement level.

A. Baklanov and

A. Kuchin

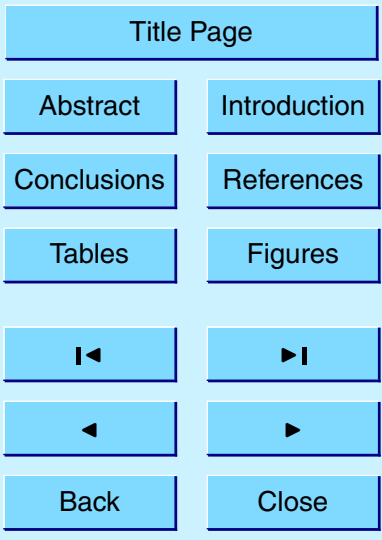

Full Screen / Esc

Print Version

Interactive Discussion

(C) EGU 2004 